\title{
THERMOLUMINESCENCE PROPERTIES OF ERBIUM DOPED SrSO
}

\author{
A.M. Moanes
}

Physics Dept., Faculty of Science Al-Azhar University, Cairo, Egypt.

\begin{abstract}
$\mathrm{SrSO}_{4}$ (strontium sulphate) has been prepared by the chemical precipitation technique and characterized by $X R D$ and TEM (Transmission Electron Microscopy). TEM shown the formation of compound in ring like structure with average particle size $45 \mathrm{~nm}$. The erbium (Er) doped to $\mathrm{SrSO}_{4}$ by different concentrations for the sake of improving the TL-sensitivity of SrSO4, were found the optimum concentration of erbium is (22wt\%). $\mathrm{SrSO}_{4}: \mathrm{Er}(0.22 \mathrm{wt} \%)$ has five glow peaks at $\left(116.5{ }^{\circ} \mathrm{C}-183{ }^{\circ} \mathrm{C}-344{ }^{\circ} \mathrm{C}-412{ }^{\circ} \mathrm{C}-431{ }^{\circ} \mathrm{C}\right)$. High gamma doses as TL-sensitization method have been used. By these means the TL-intensity of treated samples proved about 30 times enhancement, which make it very promising detector and dosimeter suitable for ionizing radiation.
\end{abstract}

Keyword : Thermoluminescence, Nanomaterials, Sensitization, Erbium and $\mathrm{SrSO}_{4}$

\section{INTRODUCTION}

Thermoluminescence (TL) is the emission of light from semiconductor or an insulator when it is heated after its exposure to radiation [1-2]. Thermoluminescence is one of the longinvestigated fields. Various aspects of TL have been theoretically as well as experimentally studied till now. $\mathrm{SrSO}_{4}$ : Er and LiF-TLD 100 are a couple of good thermoluminescent phosphors. Tissue equivalence, reusability, stability, high sensitivity, a simple glow curve structure and dose linearity are some of the characteristics of an ideal TL material. Since no phosphor can behave in an ideal way hence there have always been attempts to prepare new phosphors with improved TL characteristics or improve upon the already existing phosphors. The most widespread applications of TL phenomenon is the radiation dosimetery. in health physics, biological sciences and radiation protection. Besides this TL is a tool to study the defects and traps structure inside the host lattice [3]. The quality of TL materials depends on the used doping, on their concentration and on other factors. The lanthanids, $\mathrm{R}$ (rare earth), play a unique role in the production of high sensitivity reliable TL dosimeters [4].

Recently, researchers' interest towards nanomaterials has increased because they exhibit enhance optical, electronic and Structural properties. They have potential as efficient phosphors in display applications such as new flat panel displays with low energy excitation sources, solar energy converters, optical amplifiers and TLD phosphors. Many new physical and chemical methods of preparations have also been developed in the last two decades, nanoparticles and nanorods (powders) of several ceramic materials have been produced [5-6]. This study focus on the preparation of $\mathrm{SrSO}_{4}$ in nanostructure form by chemical precipitation method. The products were characterized by using transmission electron microscopy (TEM). The improving of TL- sensitivity of $\mathrm{SrSO}_{4}$ performed by doping with erbium, treated with different courses of heat annealing and gamma dose sensitization.

\section{MATERIAL AND METHOD}

\subsection{Preparation of $\mathrm{SrSO}_{4}$}

$\mathrm{SrSO}_{4}: \operatorname{Er}(0.05 \%, 0.18 \%, 0.2 \%, 0.22 \%$, $0.25 \%, 0.3$ wt\%) phosphors were synthesized through chemical precipitation technique [7]. AR grade $\mathrm{Sr}\left(\mathrm{NO}_{3}\right)_{2}, \quad\left(\mathrm{NH}_{4}\right)_{2} \mathrm{SO}_{4}$, $\mathrm{Er}_{2} \mathrm{O}_{3}(99.995 \%)$ were the reactants and dopants used for the synthesis of phosphors. The precipitate was subjected to a series of washing, filtering and drying and then calcined at $400^{\circ} \mathrm{C}$ for 1 hour to eliminate the traces of any other compounds or acids. Further, the material was ground well and then annealed at $1050^{\circ} \mathrm{C}$ in a programmable high temperature furnace for 3hours in air atmosphere, for the formation of good quality crystalline phosphor. The sieved fine powder is then used for subsequent characterization studies. Powder samples of 
$\mathrm{SrSO}_{4}$ : $\mathrm{Er}(0.22 \mathrm{wt} \%)$ and undoped $\mathrm{SrSO}_{4}$ were also prepared under the same conditions for the comparison studies of their TL properties.

Among the $\mathrm{SrSO}_{4}$ :Er samples with different co-donant concentrations. 0.22wt\% of Fr was the TL response of irradiated samples were measured by Harshaw 3500 series TLD reader and the characteristic glow curves of $\mathrm{SrSO} 4$ doped with different concentrations of Er have defined.

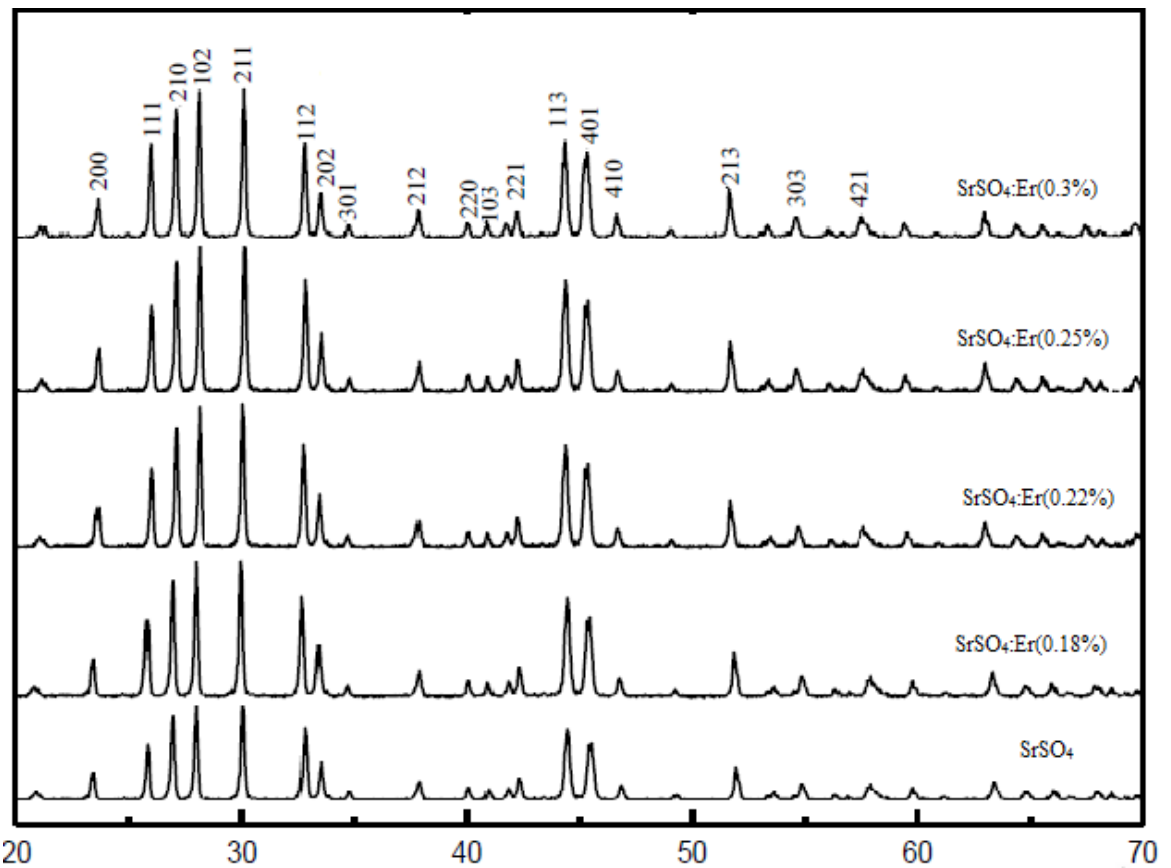

Figure (1). XRD pattern of undoped $\mathrm{SrSO}_{4}$ and $\mathrm{SrSO}_{4}$ :Er phosphors.

Table.1. Lattice Parameters and average crystallite size obtained from XRD

\begin{tabular}{c||cccc}
\hline \hline Lattice & $\mathbf{a ( A )}$ & $\mathbf{b ( A )}$ & $\mathbf{c ( A )}$ & $\mathbf{D ( n m )}$ \\
\hline \hline SrSO4 & 8.343 & 5.347 & 6.854 & 48 \\
SrSO4:Er(0.18\%) & 8.349 & 5.351 & 6.851 & 45 \\
SrSO4:Er(0.22\%) & 8.332 & 5.337 & 6.847 & 51 \\
SrSO4:Er(0.25\%) & 8.395 & 5.342 & 6.853 & 54 \\
SrSO4:Er(0.3\%) & 8.341 & 5.336 & 6.851 & 49 \\
ICDD File No. 89-0954 & 8.359 & 5.350 & 6.869 & -
\end{tabular}

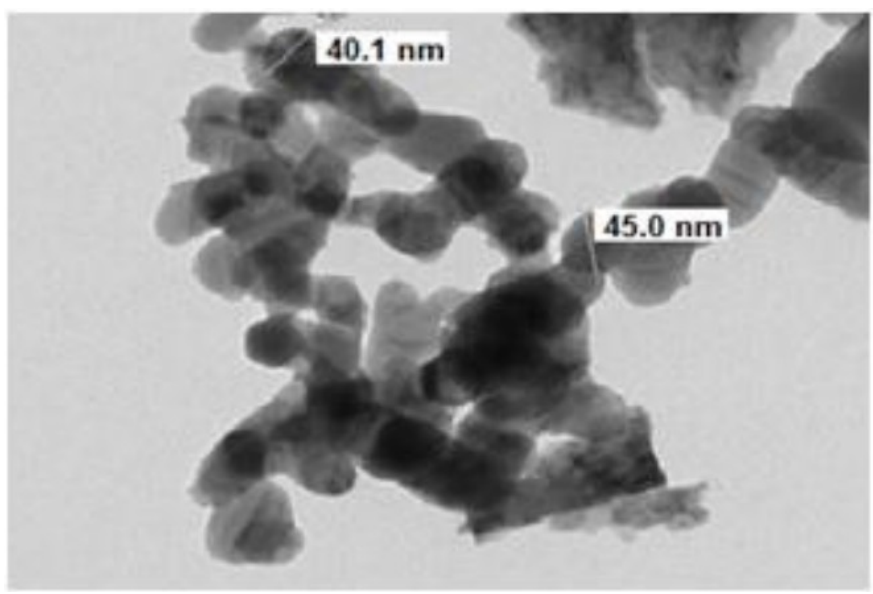

Figure (2). The TEM pattern for $\mathrm{SrSO}_{4}$. activation dose $22 \mathrm{wt} \%)$ powder $\mathrm{y}$ to measure $\mathrm{S}_{0}$ $\mathrm{SrSO}_{4}: \operatorname{Er}(0.22$ ctivation dose). $\mathrm{d}$ then irradiated Gy - 1000 Gy iy and 9000Gy). id then exposed TL response of red by Harshaw isure $\mathrm{S}$ (where $\mathrm{S}$ (0.22 wt\%) after he ratio of $\mathrm{S} / \mathrm{S} 0$ ?d dose, then the 'S0 and different d graphically in

\section{ON}

powder X-ray repared $\mathrm{SrSO}_{4}$, ll of them show in accordance - Observed and 1 the diffraction The effects of the the basic phase to the extremely be due to the sants in the Sr2+

f the phosphors sherer equation, sadening of the zalculated values c) and average ssphor are given [EM pattern for ng shape like cle size $45 \mathrm{~nm}$. 
THERMOLUMINESCENCE PROPERTIES OF ERBIUM DOPED $\mathrm{SrSO}_{4}$ 


\subsection{Thermoluminescence Studies}

\subsubsection{TL vs. activator concentration}

Figure (3). Shows the effect of different erbium concentration on the TL- intensity of SrSO4 after exposed to test dose 10Gy. It can be seen from Fig . 3 that the TL intensity firstly decrease for concentration $0.15 \mathrm{wt} \%$ after that gradually increase is observed from concentration $0.18 w t \%-0.22 w t \%$. Followed by a decrease from concentration $0.25 \mathrm{wt} \%$. The decrease in intensity may be due to the large number of energy levels produced, which might result in more number of non-radiative events. From this result the optimum concentration of Er is $0.22 w t \%$. Fig .4 shown the characteristic glow curve of $\mathrm{SrSO}_{4}: \mathrm{Er}(0.22 \mathrm{wt} \%)$, there are five peaks positions appear at $\left(116.5^{\circ} \mathrm{C}-183^{\circ} \mathrm{C}\right.$ $-344{ }^{\circ} \mathrm{C}-412{ }^{\circ} \mathrm{C}-431^{\circ} \mathrm{C}$ ) this mean that there are five different species of traps activated within our particular temperatures

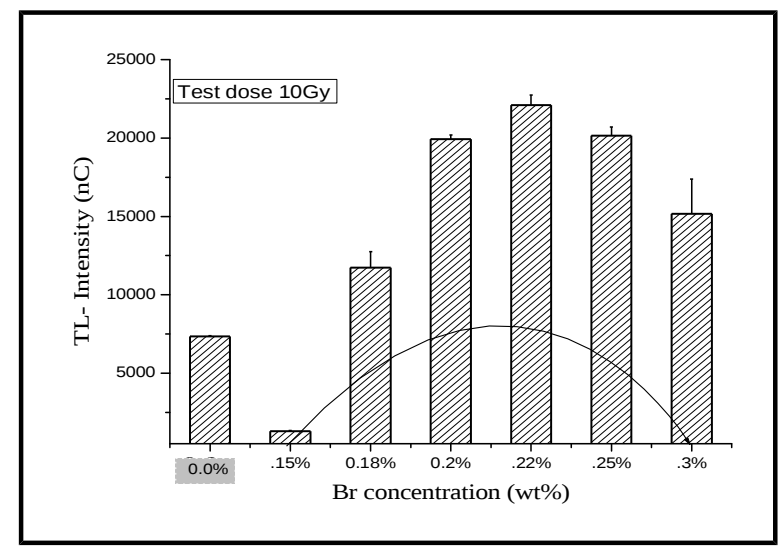

Figure (3). The effect of different erbium concentration on the TL- intensity of $\mathrm{SrSO}_{4}$ after exposed to test dose $10 G y$.

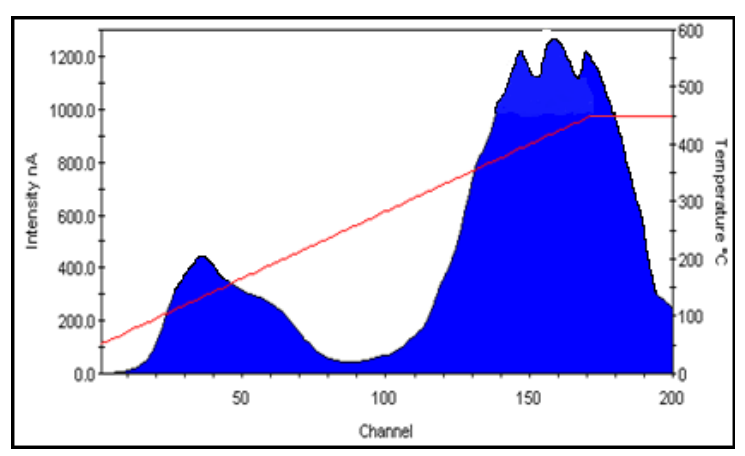

Figure (4). The characteristic glow curve of SrSO4:Er $(0.22 w t \%)$.

\subsubsection{Gamma dose Sensitization}

Figure(5) shown the effect of gamma-dose sensitization on the TL-intensity of SrSO4:Er (0.22wt\%) after exposed to test dose 10Gy. From results we can show that the TL sensitivity of $\mathrm{SrSO}_{4}: \operatorname{Er}(0.22 \mathrm{wt} \%)$ unchanged when exposed to pre doses (500 Gy and 1000 $\mathrm{Gy}$ ) then gradually increase is observed from pre- dose 3000 Gy to pre- dose 9000 Gy then decrease again. So that the optimum pre-dose is 9000Gy.

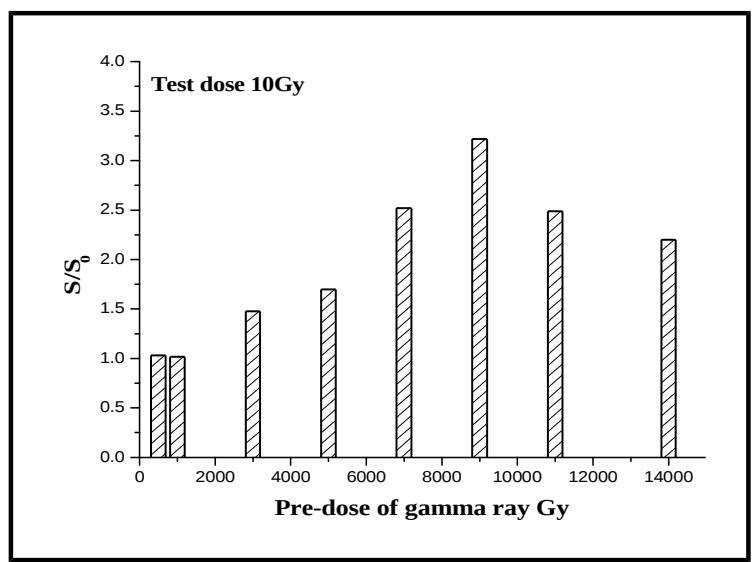

Figure (5). The effect of gamma-dose sensitization on the TL-intensity of $\mathrm{SrSO}_{4}: \mathrm{Er}(0.22 \mathrm{wt} \%)$ after exposed to test dose $10 \mathrm{~Gy}$.

\subsubsection{Gamma dose response}

In order to study the sensitivity to different doses and linearity, equal amounts of $\mathrm{SrSO}_{4}: \mathrm{Er}$ phosphor samples from the same batch of preparation were irradiated from ${ }^{60} \mathrm{Co} \gamma$ - source at room temperature with different doses in the range $1 \mathrm{~Gy}-5 \mathrm{kGy}$ and the corresponding $\mathrm{TL}$ glow curves were recorded with $\beta=4^{\circ} \mathrm{C} / \mathrm{s}$. The gamma dose response curve of the $\mathrm{SrSO}_{4}: \mathrm{Er}$ phosphor is presented in figure(6). It is observed that the phosphor exhibits almost a linear response to the dose in the range $1 \mathrm{~Gy}$ to $1 \mathrm{kGy}$. Thereafter it gets saturated. The active luminescent centers are increased with increase in $\gamma$-dose and hence the TL intensity also increases up to dose saturation. Saturation of TL intensity may be due to the reason that only a limited number of RE ions are available for charge reduction above the particular dose [1617]. Hence the phosphor may be suitable for radiation monitoring in the dose range $1 \mathrm{~Gy}-$ $1 \mathrm{kGy}$, since linearity of TL intensity against 
absorbed dose is one of the desirable criteria of a good dosimeter for personnel or environmental applications.

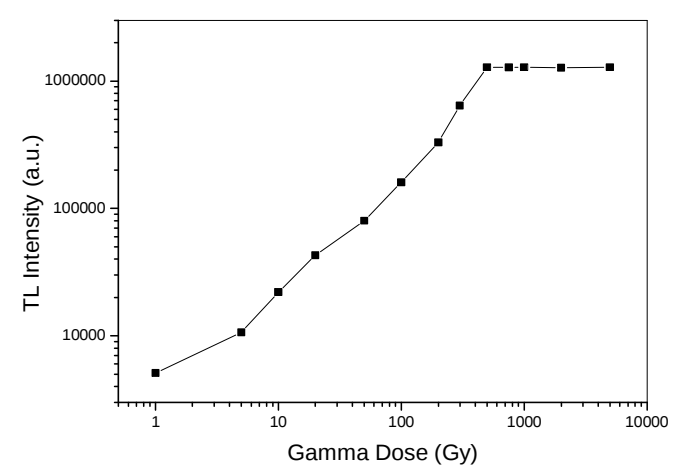

Figure (6). Dose response curve of $\mathrm{SrSO}_{4}: \mathrm{Er}(22 \mathrm{wt} \%)$ phosphor for $\gamma$-doses in the range 1Gy - 5kGy

\subsubsection{Fading}

Low fading rate is one among the primary requirements for the phosphor to be used as radiation dosimeters. Fading of TL signal leads to underestimation of absorbed dose. The fading effect of the phosphor was studied by exposing to 10Gy dose of gamma radiation and kept at room temperature in an opaque container to prevent any optical stimulation as show in figure(7). TL measurements were carried out with this sample periodically. The fading rate of the prepared $\mathrm{SrSO}_{4}$ :Er phosphor is observed to be $3 \%$ in two weeks and $5 \%$ in one month, under gamma excitation. The fading of gamma irradiated phosphor is due to the recombination of the trapped electrons released at room temperature. The phosphor with less than $20 \%$ fading rate per month at ambient temperatures up to $50^{\circ} \mathrm{C}$ is considered to be suitable for dosimetric applications [18]. But, the Commission of the European Communities suggests a fading rate of less than $5 \%$ at $25^{\circ} \mathrm{C}$ over the monitoring period suits better for dosimetric applications [19]. The fading behaviour of $\mathrm{SrSO}_{4}$ : $\mathrm{Eu}$ phosphor is better than that of the standard dosimeters TLD-200 ( $\left.\mathrm{CaF}_{2}: \mathrm{Dy}\right)$ and TLD-400 $\left(\mathrm{CaF}_{2}: \mathrm{Mn}\right)$, which have thermal fading rates of $16 \%$ in 2 weeks and 15\% in 3 weeks respectively and are widely used for short term radiation monitoring [20]. Hence the prepared $\mathrm{SrSO}_{4}: \mathrm{Eu}$ phosphor may be suitable for short term radiation monitoring.

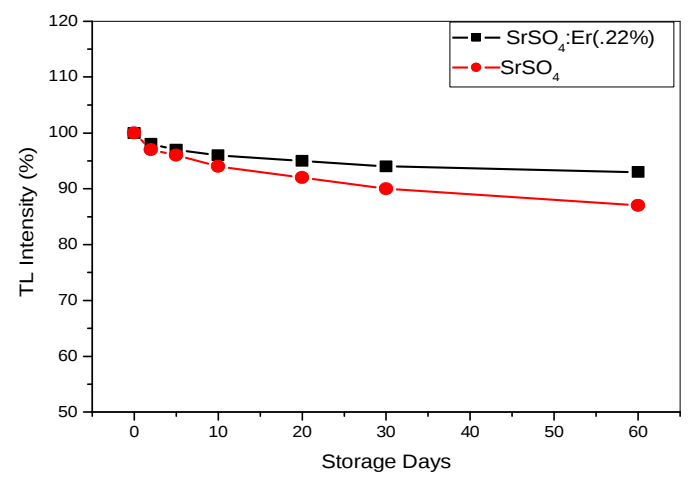

Figure (7). Fading characteristics of $\mathrm{SrSO}_{4}$ and $\mathrm{SrSO}_{4}:$ Er phosphors.

\section{CONCLUSION}

$\mathrm{SrSO}_{4}: \mathrm{Eu}$ was synthesized via chemical precipitation method. TEM micrograph shows ring like structure of the nanoparticles with an average diameter of $45 \mathrm{~nm}$. Different concentrations of Er were added to $\mathrm{SrSO}_{4}$, the result shown the optimum concentration of $\mathrm{Er}$ doped to $\mathrm{SrSO}_{4}$ (22wt\%). $\mathrm{SrSO}_{4}$ : $\mathrm{Er}(0.22 \mathrm{wt} \%)$ has five glow peaks at $\left(116.5^{\circ} \mathrm{C}-183^{\circ} \mathrm{C}-\right.$ $344^{\circ} \mathrm{C}-412^{\circ} \mathrm{C}-431^{\circ} \mathrm{C}$ ). High gamma dose sensitization have been used to increase sensitivity of $\mathrm{SrSO}_{4}$ : $\mathrm{Er}(0.22 \mathrm{wt} \%)$. From result we found that the optimum pre- dose of gamma ray is $9000 \mathrm{~Gy}$. The phosphor exhibits almost a linear response to the dose in the range $1 \mathrm{~Gy}$ to $1 \mathrm{kGy}$. The fading rate of the prepared $\mathrm{SrSO}_{4}: \mathrm{Er}$ phosphor is observed to be $3 \%$ in two weeks and $5 \%$ in one month, under gamma excitation. The fading behaviour of $\mathrm{SrSO}_{4}$ : Eu phosphor is better than that of the standard dosimeters TLD-200 ( $\left.\mathrm{CaF}_{2}: \mathrm{Dy}\right)$ and TLD-400 ( $\left.\mathrm{CaF}_{2}: \mathrm{Mn}\right)$, which have thermal fading rates of $16 \%$ in 2 weeks and $15 \%$ in 3 weeks respectively. 


\section{REFERENCE}

[1] McKeever, S. $\quad$ W. $\quad$ S., 1989. Thermluminescence of Solids. Cambridge, University Press.

[2] Mckinlay, A.F. (1981). Medical Physics Handbook of Thermoluminescence Dosimetry. Adam Higler Ltd, Bristol in collaboration with the Hospital Physicists' Association.

[3] Geeta Sharma, Puja Chawla, S. P. Lochab, Nafa Singh (2009) Chalcogenide letters. 6: 705- 712.

[4] Gscheidner, K.A., Jr and Eyring, L.(2000). " Handbook on the Physics and Chemistry of Rare Earths”. Elsevier Science B.V.

[5] Yu.V. Malyukin. (2010). journal of Radiation Measurements. 45: 589-593.

[6] Salah Numan (2010) . Radiation Physics and Chemistry. 80, : 1-10.

[7] Bhaskar Sanyala, M.Goswamib, Shobha.S, V.Prakasana, S.P.Chawlaa, M.Krishnanb, Sunil K.Ghosha (2017) .Journal of NonCrystalline Solids.475:184- 189.

[8] Satinder Kumar, A.K.Gathania, AnkushVij, RaviKumar (2016) Ceramics International. 42: 14511-14517.

[9] Jyoti Singha, J. Manam, Fouran Singh (2017) Materials Research Bulletin 94, 113121.

[10] Naglaa. Y.A. (2009). M.Sc thesis, Al-Azhar University.

[11] Koury, H.J., Guzzo, P.L., Souza, L.B.F., Farias, T.M.B., Watanaba, S. (2008). Radiation measurements.43: 487-491.

[12] C. Soliman, (2007). Nuclear Instruments and Methods in Physics Research.263: 429-435.

[13] J. Manam, S. Das, Optical Materials 31(2009)1231-1241.

[14] B.D. Cullity, Elements of X-ray Diffraction, Second Ed., Addison-Wesley Publishing Co., 1956.

[15] A. Vij et al., J. Alloys Compd. 527 (2012) 14.
[16] N. Bramhe, D.P. Bisen, R.S. Kher and M.S.K. Khokhar, Phys. Procedia 2 (2009) 431.

[17] R.K. Rai, A.K. Upadhyay, R.S. Kher, S.J. Dhoble, J. Lumin. 132 (2012) 210-214.

[18] S. Bahi, A. Pandey, S.P. Lochab, V.E. Aleynikov, A.G. Molonokov, P. Kumar, J. Lumin 134 (2013) 691-698.

[19] A.S. Pradhan, Proc. Nat. Conf. on Luminescence and its Applications, Allied Publishers, New Delhi, (1997) 83.

[20] V. Kortov, Radiat. Meas. 42(2007) 576581.0. 